\title{
Características de Mobilização de Recursos: Um Estudo nas Organizações da Sociedade Civil de Interesse Público (OSCIP) do Brasil $^{1}$
}

\author{
Features Resource Mobilization: A Study in Civil Society \\ Organizations of Public Interest (OSCIP) of Brazil
}

\section{Características de Movilización de Recursos: Un estudio en las Organizaciones de la Sociedad Civil de Interés Público (OSCIP) de Brasil}

\author{
Mércia de Lima Pereira \\ Mestranda em Ciências Contábeis UFPB \\ Endereço: Rua, Baraúnas, 351, Bairro Universitário, \\ Campina Grande, PB, Brasil, CEP: 58.429-500, Fone: \\ (83) 3315-3300, e-mail: mercia.uepb@gmail.com \\ Kallyse Priscila Soares de Oliveira, Me. \\ Professora da Universidade Estadual da Paraíba \\ Endereço: Rua, Baraúnas, 351, Bairro Universitário, \\ Campina Grande, PB, Brasil, CEP: 58.429-500, Fone: \\ (83) $3315-3300$ \\ e-mail: kallysepriscila@hotmail.com
}

\author{
Lúcia Silva Albuquerque, Me. \\ Professora da Universidade Estadual da Paraíba \\ Endereço: Rua, Baraúnas, 351, Bairro Universitário, \\ Campina Grande, PB, Brasil, CEP: 58.429-500, Fone: \\ (83) 3315-3300, e-mail: luciasalbuquerque@gmail.com \\ Fabiano Ferreira Batista, Me. \\ Professor Universidade Federal de Campina Grande \\ Doutorando Programa de Pós-Graduação em Ciências \\ Contábeis UFPB \\ Endereço: Rodovia Antônio Mariz, Br-239, Km 466, \\ Sousa, PB, CEP: $58.800-120$ \\ e-mail: fabianoferreirabatista@yahoo.com.br
}

\section{RESUMO}

O aumento no número das entidades do Terceiro Setor tem provocado concorrência entre elas por recursos financeiros e humanos, o que exige cada vez mais a utilização de estratégias por parte dessas organizações que as possibilitem manter ou mesmo assegurar a continuidade de suas atividades, projetos e/ou serviços. Neste panorama, surge o conceito de mobilização de recursos, que é mais amplo do que o de captação de recursos, pois refere-se a um esforço permanente, planejado, complexo e de fortalecimento a instituição. Assim, o objetivo deste estudo foi verificar quais são os aspectos de mobilização de recursos existentes nas OSCIPs do Brasil. A metodologia utilizada na pesquisa se classifica como bibliográfica, exploratória, descritiva e de natureza quantiqualitativa. Como instrumento de coleta de dados, utilizou-se um questionário elaborado no Google Drive que foi encaminhado a 2.272 entidades e do qual se obteve 243 questionários respondidos. Os principais resultados quanto à mobilização de recursos financeiros evidenciaram carência na utilização de ações de marketing pelas entidades e a não divulgação plena das demonstrações contábeis aos seus financiadores, embora estas entidades relacionem a prestação de contas como uma maneira de ser transparente na realização das atividades. Quanto à mobilização de recursos humanos, observou-se aspectos satisfatórios, pois de regra geral, as entidades permitem a participação de seus colaboradores por meio de sugestões. Notou-se ainda que as OSCIPs enfrentam

\footnotetext{
${ }^{1}$ Artigo recebido em 08.08.2015. Revisado pelos pares em 11.09.2015 (blind review). Ajustado e Aceito para publicação em 28.10.2015. Recomendado para publicação por José Ribamar Marques de Carvalho (Editor Científico). Publicado em 05.12.2015. Organização responsável UACC/CCJS/UFCG.
}

REUNIR: Revista de Administração, Contabilidade e Sustentabilidade ISSN: 2237-3667, Vol. 5, n. 3, p.112-131, 2015 
dificuldades em mobilizar recursos financeiros e humanos, o que pode indicar a necessidade de se aprimorar as estratégias e as informações disseminadas aos parceiros dessas entidades.

Palavras-chave: Mobilização de Recursos, Terceiro Setor, OSCIP.

\begin{abstract}
The growing number of Third Sector organizations has led to competition among these companies because for financial and human resources, which increasingly demands the use of strategies from these organizations that enable to maintain or even to ensure the continuity of their activities, projects or services. Against this background, arises the concept of resource mobilization, which is wider than the resource captivation one, since it refers to a constant, planned, complex and institutional strengthening effort. The objective of this study was to ascertain which aspects of mobilizing existing resources in the OSCIPs of Brazil. The methodology used in the research qualifies as exploratory, descriptive, bibliographical, quantitative and qualitative. As a data collection instrument, it was used a questionnaire prepared in Google Drive that was forwarded to 2,272 entities, from which 243 answers were obtained. The main results regarding the mobilization of financial resources, showed lack of marketing actions by the entities and the lack of full disclosure of the financial statements to their funders, although these entities provide accountability reports as a way to be transparent in carrying out the activities. As mobilization of human resources, satisfactory aspects were noted, because according to the general rule, the entities allow the participation of employees through their suggestions. It was noticed that the OSCIPs face difficulties in mobilizing financial and human resources, which may indicate the necessity to improve the strategies and disseminate the information to the partners of these entities.
\end{abstract}

Keywords: Resource Mobilization, Third Sector, OSCIP.

\title{
RESUMEN
}

El aumento en el número de entidades del tercer sector ha provocado la competencia entre ellos por recursos financieros y humanos, que requiere el uso de estrategias por parte de estas organizaciones que hacen posible mantener o incluso para asegurar la continuidad de sus actividades, proyectos o servicios. En este panorama, surge el concepto de movilización de recursos, que es más amplia que la recaudación de fondos porque se refiere a un esfuerzo continuo, planificado, complejo y de fortalecimiento de la institución. Así, el objetivo de este estudio era comprobar cuáles son los aspectos de movilización de recursos en OSCIPS Brasil. La metodología utilizada en la investigación se clasifica como exploratorio, descriptivo, bibliográfico y cuantitativos y cualitativos en la naturaleza. Como instrumento de recogida de datos, un cuestionario fue elaborado en la unidad de Google que fue remitido a las organizaciones de 2.272 y que obtuvo 243 cuestionarios respondidas. Los principales resultados en relación con la movilización de recursos financieros demostraron una carencia del uso de la comercialización de las acciones de las entidades y no divulgación de los Estados financieros a sus donantes, aunque estos responsabilidad de dos entidades como una manera de ser transparentes en la realización de las actividades. En cuanto a la movilización de recursos humanos mostró aspectos satisfactorios, como regla general, permite la participación de sus empleados a través de las sugerencias. Observe que las OSCIPs enfrentan dificultades en la movilización financiera y recursos humanos, que pueden indicar la necesidad de mejorar las estrategias y la información difundida a los socios de estas entidades.

Palabras clave: tercer sector, OSCIP, movilización de recursos.

\section{INTRODUÇÃO}

As organizações do Terceiro Setor são caracterizadas por serem instituições privadas, de caráter público, que não distribuem riquezas entre seus membros e/ou associados e que não visualizam o lucro como uma finalidade, mas como um meio para se alcançar o desempenho de suas funções (OLAK e NASCIMENTO, 2010).

REUNIR: Revista de Administração, Contabilidade e Sustentabilidade

ISSN: 2237-3667, Vol. 5, n. 3, p.112-131, 2015 
Neste sentido, pode-se evidenciar que, apesar de o lucro não ser o fim dessas entidades, elas precisam captar recursos financeiros para dar andamento a seus projetos e atividades. Porém, na visão de Sousa (2009), a captação de recursos não é capaz de assegurar para as organizações a durabilidade desses fundos por longos períodos.

Assim, surge o conceito de mobilização de recursos, que é mais amplo que a captação de recursos e que envolve toda uma dinâmica que deve ser efetivada numa organização com a finalidade de garantir a sua sustentabilidade. Nesse sentido, Thibes e Moretto (2011) corroboram, discorrendo que a mobilização não é somente o ato de captar recursos, mas refere-se a um esforço permanente, planejado, complexo e de fortalecimento a instituição.

Desta forma, pode-se dizer que a adoção da transparência também é um meio de se mobilizar recursos, visto que as legalidades dessas entidades são muitas vezes duvidosas, requerendo que elas sinalizem para seus financiadores e parceiros os projetos que desenvolvem, o número de beneficiados, de recursos captados e os resultados financeiros de seus exercícios; o que é possível de ser divulgado através de relatórios contábeis.

Diante do exposto, surge o seguinte questionamento: Quais as características de mobilização de recursos existentes nas OSCIPs do Brasil? Assim sendo, o objetivo geral desse estudo é verificar quais são os aspectos de mobilização de recursos presentes nas OSCIPs do Brasil.

Esse estudo se justifica pelo aumento no número das entidades do Terceiro Setor e, pela consequente dificuldade dessas organizações em adquirir ou manter a sustentabilidade de suas atividades. $O$ primeiro fato pode ser embasado por uma pesquisa realizada pelo Instituto Brasileiro de Geografia e Estatística (IBGE) e divulgada em 2012, onde se verificou que entre os anos de 2006 e 2010 houve um acréscimo no número das Entidades sem Fins Lucrativos (ESFL) de 8,8\%, passando de 267,3 mil, em 2006 para 290,7 mil em 2010. E o segundo aspecto encontra sustentação nas palavras de Carneiro et al (2011), os mesmos revelam que o contínuo aumento das entidades tem gerado competitividade entre elas na busca de recursos. Desta forma, evidencia-se a necessidade dessas entidades em implantar estratégias de mobilização de recursos.

\section{REFERENCIAL TEÓRICO}

O Terceiro Setor engloba um leque de entidades e esse termo vem sendo utilizado paralelamente a outras expressões, tais como instituições de caridade, Setor independente, Setor voluntário, entre outras. Desta forma, encontrar uma definição global para as estas não tem sido tarefa fácil. (SLOMSKI et al., 2012). 
Neste paradigma, Olak e Nascimento (2010) determinam algumas características dessas instituições: o lucro não é a razão de ser, mas o meio necessário a sua continuidade, a finalidade delas é sempre provocar mudanças sociais e os seus patrimônios são pertencentes unicamente à sociedade. Assim, as ESFL podem ser definidas como instituições privadas, que não visam o lucro como objetivo, mas como um meio para o desempenho de suas atividades, que possuem como fim a promoção do bem-estar social.

Um importante passo no que tange a legislação das organizações da sociedade civil foi o " novo marco legal do Terceiro Setor", nesta perspectiva, foi criada a Lei № 13.019/2014 que estabelece o regime jurídico das parcerias voluntárias, envolvendo ou não transferências de recursos financeiros, entre a administração pública e as organizações da sociedade civil, em regime de mútua cooperação, para a consecução de finalidades de interesse público; define diretrizes para a política de fomento e de colaboração com organizações da sociedade civil; institui o termo de colaboração e o termo de fomento. Esta referida lei altera as Leis nos 8.429, de 2 de junho de 1992, e 9.790, de 23 de março de 1999.

A Lei № 13.019/2014 traz também um conceito mais detalhado de Entidades sem Fins Lucrativos, que são agora denominadas por organização da sociedade civil que segundo $\mathrm{o}$ art. $2^{\circ}$, I:

pessoa jurídica de direito privado sem fins lucrativos que não distribui, entre
os seus sócios ou associados, conselheiros, diretores, empregados ou
doadores, eventuais resultados, sobras, excedentes operacionais, brutos ou
líquidos, dividendos, bonificações, participações ou parcelas do seu
patrimônio, auferidos mediante o exercício de suas atividades, e que os
aplica integralmente na consecução do respectivo objeto social, de forma
imediata ou por meio da constituição de fundo patrimonial ou fundo de
reserva.

Este conceito de organização da sociedade civil abrange as associações; fundações privadas, incluindo fundações de apoio de universidades públicas; serviços sociais autônomos e Organizações da Sociedade Civil de Interesse PúblicoOSCIP. A nova lei entrou em vigor apenas em 01 de agosto de 2015, pois foi prorrogada.

A nova legislação tem como prerrogativa novas regras para a assinatura de contratos entre o setor público e as organizações não governamentais. Seu objetivo principal é dar ampla transparência às transferências de recursos da União, Estados, Distrito Federal e Municípios, bem como respectivas autarquias, fundações, empresas públicas e sociedades de economia mista prestadoras de serviço público, e suas subsidiárias, com organizações da sociedade civil. Visando aprimorar a 
execução de programas, projetos e atividades de interesse público feitas pelas associações e entidades sem fins lucrativos.

\subsection{Mobilização de Recursos nas Entidades do Terceiro Setor}

Conforme Batti (2014), a mobilização de recursos refere-se ao esforço de se conseguir recursos financeiros e/ou não financeiros, seja em meio interno ou externo, para que a entidade consiga apoiar suas atividades.

O termo "mobilização de recursos" é mais amplo que a captação de recursos, pois não se limita a busca de novos financiadores, mas está atrelado a um esforço maior na busca e gerenciamento dos recursos, com vistas a garantir a continuidade da instituição. Campanhã (2011, p.23) colabora com a nomenclatura "mobilização de recursos", ao afirmar que:

\footnotetext{
Mobilizar recursos não é apenas assegurar recursos novos ou adicionais, mas também otimizar os já existentes, aumentando a eficácia e eficiência dos planos, além de obter novas parcerias e obter fontes alternativas de recursos.
}

A autora ressalta ainda que o termo "recursos" se refere tanto a dinheiro quanto a pessoas. Acrescenta-se que a mobilização de recursos agrupa ações mais abrangentes, como o uso de práticas gerenciais, campanhas educativas e marketing institucional voltado para comunidade, com a finalidade de garantir a sustentabilidade institucional (ARMANI, 2008).

\subsubsection{Mobilização de Recursos Financeiros}

Como verificado, a mobilização de recursos é uma garantia para superar o desafio da sustentabilidade nas organizações do Terceiro Setor. Armani (2008) elenca três dimensões nas quais a mesma pode ser alcançada, entre as quais está a dimensão sócio-política que trata da comunicação como um meio de favorecer a imagem da instituição e a sua credibilidade.

Com base na visão sócio-política do autor, pode-se dizer que transparência representa uma das formas de se mobilizar recursos, visto que as legalidades dessas entidades são muitas vezes duvidosas, requerendo que elas possam comunicar a seus financiadores como estão sendo aplicados os recursos recebidos. Assim, Lopes et al. (2012) confirmam este fato ao ressaltarem que as organizações que não conseguem transmitir confiança a seus financiadores sobre os recursos recebidos e utilizados não terão êxito em uma nova tentativa de captar recursos.

REUNIR: Revista de Administração, Contabilidade e Sustentabilidade ISSN: 2237-3667, Vol. 5, n. 3, p.112-131, 2015 
Neste contexto, surge um termo bastante disseminado nessas entidades, a Accountability, que conforme Nakagawa, (2007, p.17) "é a obrigação de se prestar contas dos resultados obtidos, em função das responsabilidades que decorrem de uma delegação de poder".

Assim, a contabilidade se faz necessária, possibilitando tanto a divulgação das demonstrações contábeis aos financiadores das ESFL, como o controle e monitoramento dos montantes auferidos por estas, já que contempla diversos instrumentos internos, tais como: o planejamento, controle financeiro e o gerenciamento dos recursos.

Por sua vez, o gerenciamento dos recursos pode ser feito por meio da implantação de métodos de custeio, a citar: Custeio absorção, variável e Custeio baseado em atividades. Padoveze (2012) relata que os mesmos possuem como objetivo mensurar o custo dos produtos, serviços ou atividades desenvolvidas por uma organização e está atrelado às seguintes características: quais gastos, custos e critérios devem ser utilizados para determinação do custo unitário dos produtos, serviços ou atividades desempenhadas pelas entidades.

\subsubsection{Mobilização de Recursos Humanos}

Mobilizar recursos não é uma tarefa simples e executada de um momento para outro. Desta forma, supõe-se que os indivíduos envolvidos nas entidades devam estar organizados e cientes do papel a ser desempenhado pelas organizações, ou seja, da missão e de todos os caminhos a serem percorridos, podendo os mesmos participar dos processos de decisão propondo sugestões. Armani (2008) traz uma discussão acerca deste assunto:

[...] A promoção de debates internos envolvendo todas as pessoas integrantes da organização, desde dirigentes, técnicos (as) e funcionários (as) de apoio, é fundamental para superar incompreensões e quebrar resistências, dar transparência aos processos e suas dificuldades, problematizar certas crenças e valores vividos como tabus na entidade e favorecer o processo de mudança organizacional, gerencial e cultural que se pronuncia (ARMANI, 2008 p.34).

Segundo Ruwer e Canoas (2009), o trabalho desempenhado no Terceiro Setor contempla duas forças: a do serviço remunerado, desempenhado em períodos de longo prazo e que são voltados para o desenvolvimento da entidade; e a força do trabalho voluntário, possuindo grande evidência no Terceiro Setor e sendo para este a grande força motriz, pois os voluntários desempenham atividades de curto e de médio prazo, e assim como os demais funcionários, contribuem para o conhecimento 
e capacitação das entidades onde atuam. Desta forma, pode-se aferir que apesar de executar um trabalho gratuito, os voluntários devem desempenhá-lo com eficácia, orientados por uma gestão profissionalizada.

\subsection{Estudos Afins}

Poucas pesquisas foram encontradas com a temática "Mobilização de recursos nas entidades do Terceiro Setor", por isto, acredita-se que esta seja uma nova realidade na qual essas organizações devem buscar se inserir cada vez mais, devido principalmente à concorrência pela busca de recursos financeiros que elas enfrentam. As principais investigações encontradas com o tema foram as seguintes:

Sousa (2009) identificou como se dá a mobilização de recursos, tendo em vista a garantia da sustentabilidade, em entidades do Nordeste Brasileiro inscritas no Cadastro Nacional de Entidades Ambientalistas (CNEA). Os principais resultados revelaram que: a maior dificuldade das organizações é conseguir novos doadores, a maioria das entidades não são adeptas do marketing e da análise de mercado. Observou-se ainda que todas as entidades consideram o desafio da sustentabilidade algo comprometedor à continuidade das organizações, sendo a mobilização de recursos a solução.

A pesquisa de Thibes e Moretto (2011), realizada em Florianópolis - SC, a partir de um estudo de caso submetido a uma organização da sociedade civil, com o propósito de analisar a interface da entidade com outros atores sociais no que tange a mobilização de recursos e ao alcance da sustentabilidade. Os resultados ressaltaram que a organização estudada precisa reestruturar sua estratégia de mobilização de recursos, uma vez que remete tal prática a simples captação de recursos, sem considerar a dimensão institucional da entidade.

Lopes et al. (2012) verificou como as organizações do Terceiro Setor realizam o controle financeiro dos recursos recebidos dos financiadores. Para tal procedeu com um estudo multicaso aplicado em sete organizações do Estado de Pernambuco. Os resultados indicaram falhas no processo de gestão dos recursos financeiros, a causa principal se remeteu a falta de segregação de funções da equipe que atua nos projetos e a falta do uso da contabilidade no acompanhamento e controle dos recursos.

Ochieng et al. (2012) realizaram um estudo em 14 organizações de base comunitária (OBC) do Quênia, visando examinar os fatores responsáveis por influenciar na mobilização de recursos internos, bem como na capacidade destas em mobilizar recursos de seus financiadores. Os resultados indicaram que, a inacessibilidade aos recursos do Setor empresarial, a presença de estrutura de gestão, entre outros fatores, influenciam muito na capacidade das OBC para mobilizar recursos.

REUNIR: Revista de Administração, Contabilidade e Sustentabilidade ISSN: 2237-3667, Vol. 5, n. 3, p.112-131, 2015 
Khieng (2013) elaborou um trabalho em diferentes áreas de Camboja, de abrangência nacional, com o objetivo de identificar as estratégias de mobilização de recursos implantadas pelas Organizações Não Governamentais (ONGs). Os principais resultados demonstraram que embora as doações e subvenções sejam as principais fontes de recursos, existem tendências de que nos próximos cinco anos sejam implantadas nas ONGs atividades geradoras de renda.

Uma recente pesquisa elaborada por Batti (2014) retrata as dificuldades que as Organizações Não Governamentais (ONGs) da África enfrentam para conseguir recursos. A autora elenca recomendações importantes e tendências emergentes na mobilização de recursos que podem ser utilizadas para assegurar a sustentabilidade das ONGs. Contudo, verificou-se que a mobilização de recursos requer tempo e habilidades para a busca de diferentes fontes de recursos e que a pressão para mobilizá-los pode levar as organizações a usar métodos inadequados.

Os estudos mencionados evidenciam diversas sistemáticas de estudo, porém todas abordam as dificuldades na captação de recursos por parte das entidades do Terceiro Setor e o quão importante é a implementação de uma gestão profissionalizada.

\section{PROCEDIMENTOS METODOLÓGICOS}

Esta pesquisa se apresenta como bibliográfica, exploratória, pois possibilita uma maior familiaridade com o tema pesquisado; é um estudo descritivo, pois descreve as características das OSCIPs quanto à mobilização de recursos; e é de natureza quanti-qualitativa, pois se utiliza tanto do detalhamento dos eventos quanto da análise de números para obtenção dos resultados.

Como instrumento de coleta de dados, utilizou-se o questionário semiestruturado, que foi inserido na ferramenta online, Google docs. Esse instrumento de coleta foi elaborado a partir das pesquisas de Santos (2010) e Sousa (2009). O questionário foi estruturado em dois blocos de questões a seguir elencados:

Aspectos inerentes à mobilização de recursos: relata características de mobilização de recursos financeiros e humanos presentes nas entidades;

Aspectos sobre controle e gerenciamento dos recursos: neste grupo têm-se questionamentos acerca da utilização de planejamento, orçamento e métodos de custeio pelas instituições.

O universo dessa pesquisa são as OSCIPs do Brasil. Para tal, solicitou-se ao Ministério da Justiça, utilizando-se da Lei de acesso à informação, uma listagem das entidades cadastradas e seus respectivos e-mails, o órgão por sua vez, disponibilizou informações de 4.693 organizações. No entanto, apenas 4.361 apresentavam e-mails, estas foram inicialmente consideradas a população do estudo. Os questionários 
foram enviados às 4.361 OSCIPs três vezes durante o período de 03 de Julho a 22 de outubro de 2014, e embora a pesquisa seja de âmbito nacional não se obteve respostas dos Estados de Amapá, Piauí e Roraima.

Algumas limitações envolveram o envio do questionário, como a falha de grande parte dos e-mails e a impossibilidade revelada por alguns dos responsáveis por estes em responder ao questionário, sendo os principais motivos apontados: o não enquadramento da entidade como OSCIP naquele momento, a ausência de Contador no período de envio dos questionários e o desligamento da entidade desses responsáveis pelos e-mails.

Por estes motivos, a amostra se apresenta como não probabilística e por acessibilidade e a população foi redefinida, desconsiderando as organizações que apresentaram falhas em seus e-mails e as entidades, cujos responsáveis se revelaram inaptos para o preenchimento do questionário. Assim, a população validada perfez o total de 2.772 entidades, das quais, 243 responderam ao questionário.

Os dados obtidos foram organizados em tabelas criadas a partir do software Microsoft Excel, versão 2010, após as informações foram examinadas de forma conjunta, interpretadas e apresentadas de forma descritiva.

\section{APRESENTAÇÃO E DISCUSSÃO DOS RESULTADOS}

Neste segmento serão abordadas estratégias e desafios na mobilização de recursos financeiros, a visão da entidade sobre a prestação de contas e as principais demonstrações contábeis divulgadas aos financiadores.

Tabela 1 - Estratégias utilizadas pelas entidades em suas apresentações p/ mobilizar recursos financeiros

\begin{tabular}{l|c|c|c|c|c|c}
\hline \multirow{2}{*}{ Item } & \multicolumn{2}{|c|}{ Sim } & \multicolumn{2}{c|}{ Não } & \multicolumn{2}{c}{ Total } \\
\cline { 2 - 7 } & $f i$ & $\%$ & $f i$ & $\%$ & fi & $\%$ \\
\hline Apresentação da organização & 167 & 69 & 76 & 31 & 243 & 100 \\
Apresentação do projeto (produto/serviço) & 202 & 83 & 41 & 17 & 243 & 100 \\
Análise de mercado & 40 & 16 & 203 & 84 & 243 & 100 \\
Recursos humanos envolvidos & 70 & 29 & 173 & 71 & 243 & 100 \\
Planejamento financeiro e orçamentário & 85 & 35 & 158 & 65 & 243 & 100 \\
Plano de implementação & 73 & 30 & 170 & 70 & 243 & 100 \\
\hline
\end{tabular}

Fonte: Pesquisa de Campo (2014).

A tabela 1 demonstra as estratégias utilizadas pelas organizações na mobilização de recursos financeiros. Sendo possível verificar que as táticas mais desempenhadas pelas entidades são a apresentação do projeto e a apresentação da organização com $83 \%$ e $69 \%$ respectivamente. Verifica-se que os outros tipos de estratégias não alcançaram o percentual de 50\%, sendo elas menos utilizadas pelas organizações.

REUNIR: Revista de Administração, Contabilidade e Sustentabilidade ISSN: 2237-3667, Vol. 5, n. 3, p.112-131, 2015 
Segundo Ashoka e Mckinsey (2001), a estrutura do projeto de captação de recursos contém basicamente os seguintes itens: apresentação da organização, apresentação do serviço, análise do mercado, marketing, planejamento financeiro, equipe gerencial, riscos e oportunidades e plano de implementação. Cabendo salientar que, quanto mais claro for o projeto, mais fácil se torna as chances de que um possível financiador venha a financiá-lo.

Tabela 2 - Primeiro Contato das organizações com os investidores.

\begin{tabular}{l|c|c}
\hline Primeiro contato com investidores & $f i$ & $\%$ \\
\hline Através de um profissional de captação de recursos & 51 & 21 \\
Network pessoal do(s) principal (is) gestor (es) da organização & 114 & 47 \\
Através de voluntários & 45 & 18 \\
Através de ações de marketing (telemarketing, empresas & 11 & 5 \\
parceiras, eventos) & 22 & 9 \\
Outros & 243 & 100 \\
\hline Total &
\end{tabular}

Fonte: Pesquisa de Campo (2014).

A pesquisa procurou identificar como se estabelece o primeiro contato entre as entidades e seus investidores. Na tabela 2, identifica-se que em $47 \%$ das organizações ocorre pela interação pessoal do (s) gestor (es), seguido por $21 \%$ das entidades que o estabelecem por meio de um profissional de captação de recursos, em $18 \%$ das organizações são os voluntários que realizam essa atividade. Este estudo apresenta aspecto divergente da pesquisa elaborada por Sousa (2009), na qual se observou que o primeiro contato das OSCIPs com seus parceiros se estabelecem principalmente por meio de um profissional de captação de recursos, o que pode indicar que as instituições, objeto do presente estudo, demandem de mais profissionais voltados exclusivamente para esta função.

Por outro lado, Thibes e Moretto Neto (2011), revelam que alguns pesquisadores verificaram que não existe dentro das organizações do Terceiro Setor uma pessoa voltada exclusivamente para a função de mobilizar recursos, nem a concepção de que este seria um papel a ser desempenhado por todos os indivíduos envolvidos na entidade.

Observou-se ainda que apenas 5\% das entidades realizam ações de marketing. Dado similar ao alcançado pelo estudo de Sousa (2009), que constatou que $80 \%$ das entidades não utilizam ações de marketing, trazendo um dado preocupante, pois esta seria uma forma de conscientizar a comunidade sobre a ação social realizada por estas instituições e de promover ações educativas para se conquistar novos doadores. 
Tabela 3 - Quanto ao processo de mobilização de recursos financeiros nas entidades

\begin{tabular}{|c|c|c|c|c|c|c|}
\hline É um desafio para as organizações & \multicolumn{3}{|c|}{$f i$} & \multicolumn{3}{|c|}{$\%$} \\
\hline Sim & \multicolumn{3}{|c|}{235} & \multicolumn{3}{|c|}{97} \\
\hline Não & \multicolumn{3}{|c|}{8} & \multicolumn{3}{|c|}{3} \\
\hline Total & \multicolumn{3}{|c|}{243} & \multicolumn{3}{|c|}{100} \\
\hline \multirow{2}{*}{ Dificuldades do processo } & \multicolumn{2}{|c|}{ Sim } & \multicolumn{2}{|c|}{ Não } & \multicolumn{2}{|c|}{ Total } \\
\hline & $F i$ & $\%$ & $f i$ & $\%$ & $f i$ & $\%$ \\
\hline Conseguir novos doadores & 177 & 73 & 66 & 27 & 243 & 100 \\
\hline Manter os doadores existentes fiéis & 106 & 44 & 137 & 56 & 243 & 100 \\
\hline $\begin{array}{l}\text { Superar propostas de outras entidades } \\
\text { concorrentes }\end{array}$ & 36 & 15 & 207 & 85 & 243 & 100 \\
\hline Elaborar projetos diversificados e viáveis & 108 & 44 & 135 & 56 & 243 & 100 \\
\hline Avaliar o desempenho da organização & 43 & 18 & 200 & 82 & 243 & 100 \\
\hline Atender as exigências dos investidores & 54 & 22 & 189 & 78 & 243 & 100 \\
\hline Atrair bons voluntários e /ou funcionários & 84 & 35 & 159 & 65 & 243 & 100 \\
\hline
\end{tabular}

Fonte: Pesquisa de Campo (2014).

De acordo com o exposto na tabela 3, observa-se que existe desafio em mobilizar recursos financeiros em $97 \%$ das organizações, ou seja, essa deficiência é quase que unânime nas entidades estudadas. Entre os obstáculos revelados pelas OSCIPs estão às dificuldades em conseguir novos doadores, representando um percentual de $73 \%$, para $44 \%$ das entidades a dificuldade maior está em manter os doadores fiéis e em elaborar projetos diversificados. Para 22\%, $18 \%$ e $15 \%$, respectivamente, o maior contratempo é atender as exigências dos investidores, avaliar o desempenho da organização e superar propostas de outras entidades concorrentes.

Esse estudo evidenciou características semelhantes à pesquisa de Sousa (2009), que demonstrou que 100\% das ESFL enfrentam dificuldades em mobilizar recursos financeiros e que a dificuldade maior está em conseguir atrair novos doadores, sinalizando uma preocupação generalizada das ESFL quanto a esse aspecto.

Em um estudo realizado por Khieng et al. (2013), verificou-se que apesar da dependência de doações, as Organizações Não Governamentais (ONGs) do Camboja estão buscando cada vez mais gerar renda internamente, através de comercialização de produtos ou serviços. Assim, esta é uma tendência capaz de garantir a sustentabilidade financeira da instituição, diminuir a dependência por recursos de terceiros e os problemas de escassez de recursos. 
Nesta pesquisa objetivou-se também verificar como as OSCIPs vislumbram a prestação de contas.

Tabela 4 - Percepção das entidades quanto à prestação de contas

\begin{tabular}{l|c|c|c|c|c|c}
\hline \multirow{2}{*}{\multicolumn{1}{c|}{ Item }} & \multicolumn{2}{c|}{ Sim } & \multicolumn{2}{c|}{ Não } & \multicolumn{2}{c}{ Total } \\
\cline { 2 - 7 } & $f i$ & $\%$ & $f i$ & $\%$ & $f i$ & $\%$ \\
\hline Uma forma de atrair financiadores & 90 & 37 & 153 & 63 & 243 & 100 \\
Uma imposição do governo & 104 & 43 & 139 & 57 & 243 & 100 \\
Favorecedor da gestão das OSCIPs & 123 & 51 & 120 & 49 & 243 & 100 \\
Uma forma de ser transparente nas ações & 211 & 87 & 32 & 13 & 243 & 100 \\
Outros & 6 & 2 & 237 & 98 & 243 & 100 \\
\hline
\end{tabular}

Fonte: Pesquisa de Campo (2014).

Conforme tabela $4,87 \%$ das entidades visualizam a prestação de contas como uma maneira de ser transparente nas ações realizadas, 51\% como uma favorecedora na gestão da organização, $43 \%$ vê esse processo como uma obrigação imposta pelo governo, $37 \%$ das entidades vislumbra como um atrativo para captar novos parceiros, e somente $2 \%$ das organizações tem outras percepções sobre prestação de contas.

Contudo, verificou-se que as entidades possuem uma visão positiva do que a prestação de contas possa representar, pois consideram como sendo uma ferramenta que as possibilita agir de forma transparente na realização de suas atividades. Carneiro et al (2011) referem-se à transparência como sendo uma estratégia competitiva, capaz demonstrar quem é a entidade e quais são seus reais objetivos. Desta forma, pode-se dizer que as entidades possuem uma concepção correta da prestação de contas e que estão cada vez mais conscientes de importância da mesma para se conseguir mobilizar recursos.

$\mathrm{Na}$ tabela 5 destaca-se as demonstrações elaboradas pelas entidades para prestar contas a cada tipo de financiador. Conforme Resolução CFC N.o 1.409/12 que aprovou a ITG 2002 - Entidade sem Finalidade de Lucros (item 22-25), as demonstrações contábeis que devem ser elaboradas pela entidade sem finalidade de lucros são o Balanço Patrimonial, a Demonstração do Resultado do Período, a Demonstração das Mutações do Patrimônio Líquido, a Demonstração dos Fluxos de Caixa e as Notas Explicativas, conforme também previsto na NBC TG 26(R1), quando aplicável. 
Tabela 5 - Demonstrações Contábeis (DCs) elaboradas para prestação de contas aos financiadores

\begin{tabular}{|c|c|c|c|c|c|c|c|c|c|c|c|c|c|c|c|c|}
\hline \multirow{3}{*}{ DCs } & \multicolumn{4}{|c|}{ Governo } & \multicolumn{4}{|c|}{$\begin{array}{c}\text { Agências de } \\
\text { financiamento }\end{array}$} & \multicolumn{4}{|c|}{ Doadores } & \multicolumn{4}{|c|}{ Comunidade } \\
\hline & \multicolumn{2}{|c|}{ Sim } & \multicolumn{2}{|c|}{ Não } & \multicolumn{2}{|c|}{ Sim } & \multicolumn{2}{|c|}{ Não } & \multicolumn{2}{|c|}{ Sim } & \multicolumn{2}{|c|}{ Não } & \multicolumn{2}{|c|}{ Sim } & \multicolumn{2}{|c|}{ Não } \\
\hline & $f i$ & $\%$ & $f i$ & $\%$ & $f i$ & $\%$ & $f i$ & $\%$ & $f i$ & $\%$ & $f i$ & $\%$ & $f i$ & $\%$ & $f i$ & $\%$ \\
\hline $\mathrm{BP}$ & 199 & 82 & 44 & 18 & 209 & 86 & 34 & 14 & 223 & 92 & 20 & 8 & 204 & 84 & 39 & 16 \\
\hline DSD & 147 & 60 & 96 & 40 & 147 & 60 & 96 & 40 & 175 & 72 & 68 & 28 & 150 & 62 & 93 & 38 \\
\hline DOAR & 127 & 52 & 116 & 48 & 115 & 47 & 128 & 53 & 150 & 62 & 93 & 38 & 120 & 49 & 123 & 51 \\
\hline RAT & 143 & 59 & 100 & 41 & 148 & 61 & 95 & 39 & 231 & 95 & 12 & 5 & 198 & 81 & 45 & 19 \\
\hline DVA & 40 & 16 & 203 & 83 & 30 & 12 & 213 & 88 & 54 & 22 & 189 & 78 & 42 & 17 & 201 & 83 \\
\hline BS & 77 & 32 & 166 & 68 & 82 & 34 & 161 & 66 & 116 & 48 & 127 & 52 & 110 & 45 & 133 & 55 \\
\hline DMPL & 83 & 34 & 160 & 66 & 81 & 33 & 162 & 67 & 88 & 36 & 155 & 64 & 74 & 30 & 169 & 70 \\
\hline NE & 124 & 51 & 119 & 49 & 113 & 46 & 130 & 53 & 143 & 59 & 100 & 41 & 110 & 45 & 133 & 55 \\
\hline DFC & 109 & 45 & 134 & 55 & 97 & 40 & 146 & 60 & 132 & 54 & 111 & 46 & 94 & 39 & 149 & 61 \\
\hline
\end{tabular}

Legenda: BP: Balanço Patrimonial; DSD: Demonstração do Superávit ou Déficit; DOAR: Demonstração das origens e aplicações de recursos; RAT: relatório da administração; DVA: Demonstração do valor adicionado; BS: Balanço Social; DMPL: Demonstração das Mutações do Patrimônio Líquido; NE: Notas Explicativas; DFC: Demonstração do Fluxo de Caixa.

Fonte: Pesquisa de Campo (2014).

Na prestação de contas ao governo, verificou-se que as demonstrações contábeis mais utilizadas foram o balanço patrimonial com $82 \%$, seguido pela DSD com $60 \%$, RAT representou 59\%, DOAR 52\% e NE com 51\%.

Os principais relatórios contábeis elaborados para prestação de contas às agências de financiamento são o BP, com $86 \%$ das respostas, o RAT, com um percentual de $61 \%$ e a Demonstração do Superávit ou Déficit do Exercício que possui $60 \%$ das afirmações.

No que tange à prestação de contas à comunidade, a investigação indicou que os relatórios mais utilizados são: BP com $84 \%$, RAT com $81 \%$ e a DSD com $62 \%$.

Quanto à prestação de contas para com os doadores, o estudo revelou a existência de divergências entre estes e os outros usuários da prestação de contas, tais como: o governo, a agências de financiamentos e a comunidade, pois as demonstrações mais utilizadas para a prestação de contas aos doadores foi o RAT evidenciado por $95 \%$ das OSCIPs, o BP, que foi indicado por $92 \%$ das entidades e a DSD (72\%).

Portanto, os dados demonstram que as organizações pesquisadas não estão cumprindo de forma efetiva um dos requisitos elementares que é a prestação de contas, ou seja, nenhuma das demonstrações que são divulgadas aos investidores atingiu o percentual esperado de 100\%. Constatou-se ainda a existência de 
desvinculação entre a prestação de contas por meio do BP e da DSD, já que essas demonstrações deveriam ter percentuais equivalentes, pois parte da elaboração do BP depende da DSD.

Serão abordadas características relativas aos recursos humanos das OSCIPs. Com relação ao grau de participação dos recursos humanos (tabela 6), verifica-se que maior parte das entidades (58\%) realizam pesquisas para medir a satisfação de seus colaboradores com o ambiente de trabalho. 61\% das organizações permitem a participação dos colaboradores no planejamento, execução e avaliação de atividades e serviços desenvolvidos, e $42 \%$ das entidades criam espaços para que os funcionários possam participar da definição e controle dos custos e orçamentos das atividades ou serviços desenvolvidos.

Tabela 6 - Grau de participação dos recursos humanos nas OSCIPs

\begin{tabular}{l|c|c|c|c|c|c}
\hline \multirow{2}{*}{ Item } & \multicolumn{2}{|c|}{ Sim } & \multicolumn{2}{l|}{ Não } & \multicolumn{2}{|c}{ Total } \\
\cline { 4 - 7 } & $f i$ & $\%$ & $f i$ & $\%$ & $f i$ & $\%$ \\
\hline $\begin{array}{l}\text { A entidade realiza pesquisa s/ a satisfação deles em relação às } \\
\text { ações desenvolvidas? }\end{array}$ & 141 & 58 & 102 & 42 & 243 & 100 \\
\hline $\begin{array}{l}\text { Eles Participam do planejamento, execução e avaliação dos } \\
\text { serviços oferecidos? }\end{array}$ & 149 & 61 & 94 & 39 & 243 & 100 \\
\hline $\begin{array}{l}\text { A entidade criou espaços para que eles participassem da } \\
\text { definição e controle de custos/ orçamentos destinados para as } \\
\text { atividades e serviços oferecidos? }\end{array}$ & 101 & 42 & 142 & 58 & 243 & 100 \\
\hline
\end{tabular}

Fonte: Pesquisa de Campo (2014).

Desta forma, observou-se que as organizações buscam saber o feedback de seus recursos humanos quanto à suas atividades, que estes são atuantes no planejamento e execução dos serviços oferecidos e no que se refere ao controle de custos/orçamentos das atividades ou serviços oferecidos, os recursos humanos não participam de forma tão incisiva.

Batti (2014) revela que um dos desafios que envolvem a mobilização de recursos é a "síndrome do fundador", ou seja, quando os fundadores controlam as organizações com o mínimo de participação de outras pessoas, não estando estes dispostos a utilizar novos métodos de interação entre os membros existentes na entidade. Assim, verifica-se que em algumas atividades desenvolvidas em grande parte das entidades estudadas este paradigma tem sido quebrado.

Além disso, procurou-se averiguar se as entidades possibilitam a exposição de sugestões gerais pelos recursos humanos.

Tabela 7 - Quanto à apresentação de sugestões gerais pelos Recursos Humanos da organização

\begin{tabular}{c|c|c|c|c}
\hline \multirow{2}{*}{ Item } & \multicolumn{2}{|c|}{ Funcionários } & \multicolumn{2}{c}{ Voluntários } \\
\cline { 2 - 5 } & $\mathrm{fi}$ & $\%$ & $\mathrm{fi}$ & $\%$ \\
\hline
\end{tabular}

REUNIR: Revista de Administração, Contabilidade e Sustentabilidade ISSN: 2237-3667, Vol. 5, n. 3, p.112-131, 2015 


\begin{tabular}{l|c|c|c|c}
\hline Sim & 206 & 85 & 205 & 84 \\
Não & 37 & 15 & 38 & 16 \\
\hline Total & 243 & 100 & 243 & 100 \\
\hline
\end{tabular}

Fonte: Pesquisa de Campo (2014).

Conforme a tabela 7, 85\% dos funcionários apresentam sugestões gerais às organizações no desempenho das atividades e $84 \%$ dos voluntários também possuem este espaço, o que permite concluir que tanto os funcionários como os voluntários possuem de forma similar participação direta na organização, revelando, portanto, aspectos satisfatórios quanto à mobilização de recursos humanos.

Tabela 8 - Dificuldades em contratar/ mobilizar bons profissionais

\begin{tabular}{l|c|c}
\hline Item & $f i$ & $\%$ \\
\hline Sim & 150 & 62 \\
Não & 93 & 38 \\
\hline Total & 243 & 100 \\
\hline MOTIVOS DA DIFICULDADE EM CONTRATAR BONS PROFISSIONAIS & $f i$ & $\%$ \\
\hline Falta de recursos financeiros devido à escassez de parceiros & 158 & 65 \\
Alta concorrência entre as entidades por esses profissionais & 4 & 2 \\
Ausência desses profissionais no mercado & 50 & 21 \\
Falta de vantagens para oferecer aos profissionais & 20 & 8 \\
Outros & 11 & 4 \\
\hline Total & 243 & 100 \\
\hline
\end{tabular}

Fonte: Pesquisa de Campo (2014).

Questionou-se às entidades sobre a existência de dificuldades na mobilização de bons profissionais (tabela 8), os resultados obtidos evidenciaram que 150 entidades (62\%) enfrentam desafios na mobilização/ contratação de bons profissionais para a entidade. Quando perguntadas quais seriam estes motivos, os mais abordados foram: a falta de recursos financeiros $(65 \%)$ e a ausência de bons profissionais no mercado (21\%). Neste contexto, entende-se que o último seja consequência do primeiro, pois para esses profissionais, outros Setores podem ser mais atrativos financeiramente.

De maneira geral, percebe-se que o problema na contratação de bons colaboradores reside, principalmente, na falta de recursos financeiros por parte das entidades.

Nesta última parte da análise dos resultados serão apresentadas questões relacionadas a métodos de custeio, planejamento e orçamento. As organizações foram questionadas sobre a utilização de cálculo para apuração dos custos de serviços oferecidos e quais os métodos de custeio são utilizados.

A tabela 9 demonstra que 175 entidades (72\%) calculam os custos dos serviços, destes $44 \%$ utilizam o custeio variável, $18 \%$ o custeio variável e custeio por absorção

REUNIR: Revista de Administração, Contabilidade e Sustentabilidade

ISSN: 2237-3667, Vol. 5, n. 3, p.112-131, 2015 
ao mesmo tempo, 4\% e 3\%, respectivamente, utilizam o custeio ABC e o método por absorção e uma parcela considerável de organizações (31\%) não souberam afirmar o método adotado, o que pode ser um dado alarmante, tendo em vista que a determinação do método de custeio é uma importante informação gerencial, que norteia o cálculo final do projeto/atividade, e que se tratando de entidades com recursos financeiros escassos, estes devem ser geridos da melhor maneira possível.

Tabela 9 - Organização calcula os custos dos serviços/atividades/projetos?

\begin{tabular}{l|c|c}
\hline Item & $f i$ & $\%$ \\
\hline Sim & 175 & 72 \\
Não & 68 & 28 \\
\hline Total & 243 & 100 \\
\hline QUAL O MÉTODO DE CUSTEIO & $f i$ & $\%$ \\
\hline Variável & 78 & 44 \\
Absorção & 5 & 3 \\
Variável e absorção & 31 & 18 \\
Custeio ABC & 7 & 4 \\
Não sabe afirmar & 54 & 31 \\
\hline Total & 175 & 100 \\
\hline
\end{tabular}

Fonte: Pesquisa de Campo (2014).

A realização do planejamento e do orçamento foi outra questão aplicada às entidades. De acordo com a tabela 10, é possível verificar que $90 \%$ das organizações realizam tanto o planejamento financeiro quanto o orçamento, e que apenas $10 \%$ das OSCIPs não elaboram estes instrumentos.

Tabela 10 - Quanto à elaboração de planejamento e orçamento

\begin{tabular}{|c|c|c|c|c|c|c|c|}
\hline \multirow{2}{*}{ Item } & & \multicolumn{2}{|c|}{ Sim } & \multicolumn{2}{|c|}{ Não } & \multicolumn{2}{|c|}{ Total } \\
\hline & & $f i$ & $\%$ & $F i$ & $\%$ & fi & $\%$ \\
\hline $\begin{array}{l}\text { Planejamento } \\
\text { Orçamento }\end{array}$ & $\mathrm{e}$ & 218 & 90 & 25 & 10 & 243 & 100 \\
\hline
\end{tabular}

Fonte: Pesquisa de Campo (2014).

Essas medidas gerenciais são de grande importância para estas entidades, pois traçam e quantificam as estratégias a serem implementas/utilizadas e o alto percentual de entidades que as utilizam sinaliza uma gestão satisfatória nestas organizações.

\section{CONSIDERAÇÕES FINAIS}

O objetivo desta pesquisa foi verificar as características de mobilização de recursos existentes nas OSCIPs do Brasil. Com relação às estratégias para mobilizar recursos financeiros, constatou-se que a maior parte das entidades adota a 
apresentação do projeto. Observou-se ainda que as entidades carecem de ações de marketing, que poderia ser uma forma de comunicar a sociedade sobre a atuação social desempenhada pelas OSCIPs e de se conquistar novos doadores, já que a prospecção destes é justificado por $73 \%$ delas como sendo o principal desafio na mobilização de recursos financeiros.

Com relação à prestação de contas, verificou-se que as entidades possuem uma visão positiva do que a mesma possa representar visto que a associa a transparência na realização das tarefas, porém notou-se que as OSCIPs não estão divulgando as demonstrações contábeis de forma plena. Além disso, constatou-se discrepância entre as demonstrações prestadas aos doadores e aos demais financiadores como o governo, a comunidade e as agências de financiamento e certa desvinculação entre a prestação por meio do Balanço Patrimonial e da Demonstração do Déficit ou Superávit do Período, relatórios que deveriam ser prestados concomitantemente, uma vez que o primeiro decorre em partes do segundo.

No que tange a mobilização de recursos humanos observa-se que as entidades revelaram ter dificuldades em mobilizar bons profissionais, sendo o principal obstáculo, a falta de recursos financeiros. Identificou-se ainda, de regra geral, que os recursos humanos, tanto voluntários como funcionários, expõem sugestões inerentes à realização das atividades-fim das OSCIPs.

Contudo, observa-se que as entidades devem se ater com mais veemência à aplicação de estratégias de marketing e a prestação de contas no que concerne à divulgação efetiva das demonstrações, visando superar os desafios da mobilização de recursos financeiros e humanos.

Como sugestões para futuras pesquisas, propõe-se a realização de pesquisas semelhantes, com comparações entre as práticas de mobilização de recursos realizadas pelas OSCIP e por outras entidades classificadas também como do Terceiro Setor.

\section{REFERÊNCIAS}

ARMANI, D. Mobilizar para transformar: a mobilização de recursos nas organizações da sociedade civil. São Paulo: Peirópolis; Recife, PE: Oxfam, 2008.

ASHOKA EMPREENDEDORES SOCIAIS E MCKINSEY \& COMPANY INC. Empreendimentos sociais sustentáveis: como elaborar planos para organizações sociais. São Paulo: Peirópolis, 2001.

BATTI, R. C. Challenges Facing Local NGOs in Resource Mobilization. Humanities and Social Sciences. v. 2, n. 3, p. 57-64, mai.,2014. Disponível em: < 
http://article.sciencepublishinggroup.com/pdf/10.11648.j.hss.20140203.12.pdf> Acesso em: 30 out.2014.

BRASIL. Lei № 9.790, de 23 de março de 1990. Dispõe sobre a qualificação de pessoas jurídicas de direito privado, sem fins lucrativos, como Organizações da Sociedade Civil de Interesse Público, institui e disciplina o Termo de Parceria e dá outras providências. Disponível em: <https://www.planalto.gov.br/>. Acesso em: 22 Ago.2014.

LEI FEDERAL № № 13.019/2014. Estabelece o regime jurídico das parcerias voluntárias, envolvendo ou não transferências de recursos financeiros, entre a administração pública e as organizações da sociedade civil, em regime de mútua cooperação, para a consecução de finalidades de interesse público. Disponível em: https://www.planalto.gov.br. Acesso em 23/03/ 2015.

. Resolução 1.409, de 21 de setembro de 2012. Aprova a ITG 2002 -

Entidades sem finalidade de lucros. Diário Oficial, Brasília, DF, 27. set. 2012. Disponível

em:

http://www.cfc.org.br/sisweb/sre/detalhes_sre.aspx?Codigo=2012/001409>. Acesso em: 24.maio. 2014.

. Resolução NBCTG26(R1), de 11 de dezembro de 2013. Altera a NBC TG 26 que dispõe sobre apresentação das demonstrações contábeis. Diário Oficial, Brasília, 20. dez. 2013. Disponível em: < http://www.cfc.org.br/sisweb/sre/detalhes_sre.aspx?codigo=2013/NBCTG26(R1)>. Acesso em: 24.maio. 2014.

CAMPANHÃ, M. R. A comunicação na captação de recursos em Organizações Sem Fins Lucrativos. Estudo de caso sobre o SOS - Casas da Acolhida. Monografia, Porto Alegre: UFRS, 2011. Disponível em: < https://www.lume.ufrgs.br/bitstream/handle/10183/37588/000822591.pdf?sequence=1 >Acesso em: 20. Ago. 2014.

CARNEIRO, A. de F.; OLIVEIRA, D. de L.; TORRES, L. C. Accountability e a prestação de contas das organizações do Terceiro Setor: uma abordagem à relevância da contabilidade. Sociedade, contabilidade e gestão. v. 6, n. 2, p. 90-105, jul./dez.,2011. Disponível em: < http://www.atena.org.br/revista/ojs-2. 2.306/index.php/ufrj/article/view/1206> Acesso em: 17.out.2014. 
Instituto Brasileiro de Geografia e Estatística (IBGE). As Fundações Privadas e Associações Sem fins Lucrativos no Brasil. Rio de Janeiro: IBGE, 2012. Disponível em: http://ftp.ibge.gov.br/Fundacoes_Privadas_e_Associacoes/2010/fasfil.pdf $>$.Acesso em: 22 ago.2014.

KHIENG, S. Funding Mobilization Strategies of Nongovernmental Organizations in Cambodia. Voluntas: International Journal of Voluntary and Nonprofit Organizations, Ago.,2013.___ Disponível em: < http://link.springer.com/article/10.1007/s11266-013-9400-7> Acesso em: 25 out.2014.

LOPES, L. da C.; ANDRADE, C. S.; MEIRA, J. M.; SANTOS, A. A.; FERREIRA, J. O. L. A. Um estudo Multicaso sobre a Gestão de Recursos Financeiros em Organizações do Terceiro Setor. Revista de Contabilidade e Controladoria, Curitiba, v.4, n.3, p. 2436, set/dez.,2012. Disponível em:< http://ojs.c3sl.ufpr.br/ojs/index.php/rcc/article/view/29835> Acesso em: 29 out.2014.

NAKAGAWA, M. Introdução à controladoria: conceitos, sistemas, implementação. 1. Ed. - São Paulo: Atlas, 2007.

OCHIENG, B. M.; et al. Factors Influencing Mobilization of Kenyan Resources for Health and Development. International J. Soc. Sci. \& Education, v. 3, 2012. Disponível em:

http://eprints.usq.edu.au/22041/1/Ochieng_Mala_Mumbo_Aila_Odera_PV.pdf> Acesso em: 02 nov. 2014.

OLAK, P. A.; NASCIMENTO, D. T. do. Contabilidade para entidades sem fins lucrativos (Terceiro Setor). 3. Ed - São Paulo: Atlas, 2010.

PADOVEZE, C. L. Controladoria Estratégia e Operacional: Conceitos, estrutura, aplicação. 3. Ed. rev. e atual.-São Paulo: Thomson Learning,2012.

RUWER, L. M. E.; CANOAS, J. W. Gestão de Pessoas Em Organizações do Terceiro Setor: Especificidades Dos Recursos Humanos, Perspectivas e Desafios - Notas Introdutórias. Revista Serviço Social \& Realidade. v. 18, n. 2, p. 107-132, 2009. Disponível em: http://periodicos.franca.unesp.br/index.php/SSR/article/view/132/180>. Acesso em: 10 nov.2014. 
SANTOS, C. A. dos. Práticas de contabilidade das organizações sem fins lucrativos de Curitiba. Dissertação (Mestrado) - Universidade Federal do Paraná. Programa de Pós- Graduação em Contabilidade, do Setor de Ciências Sociais Aplicadas: Curitiba, 2010.

SLOMSKI, V.; REZENDE, A. J.; CRUZ, C. V. O. A.; OLAK. P; A. Contabilidade do Terceiro Setor: uma abordagem operacional aplicável às associações, fundações, partidos políticos e organizações religiosas. São Paulo: Atlas, 2012.

SOUSA, D. A. A. A Mobilização de Recursos Como Garantia da Sustentabilidade: Um estudo de Multivariado com Entidades ambientalistas no Nordeste Brasileiro. Monografia, Sousa: UFCG, 2009.

THIBES, M. M.; MORETTO NETO, L. Mobilização de Recursos nas Organizações da Sociedade Civil: Um Estudo de Caso. Revista Pretexto, Belo Horizonte, v.12, p.134144, n.4, out/dez., $2011 . \quad$ Disponível em: $<$ http://www.fumec.br/revistas/pretexto/article/view/826/639>. Acesso em: 8 out.2014. 